\title{
PEMBERDAYAAN MASYARAKAT MELALUI PENDAMPINGAN PROGRAM KERJA BERBASIS MANAJEMEN LINGKUNGAN
}

\author{
Novita Wahyu Setyawati ${ }^{1}$, Dewi Sri Woelandari P.G ${ }^{2}$ \\ Fakultas Ekonomi Manajemen, Universitas Bhayangkara Jakarta Raya Bekasi, Indonesia \\ novita.wahyu@dsn.ubharajaya.ac.id
}

\begin{abstract}
ABSTRAK
Abstrak: Kegiatan pengabdian ini bertujuan untuk membangun kepedulian masyarakat di Kota Bekasi agar dapat 'berkawan' dengan lingkungan sekitarnya untuk mendapatkan manfaat secara langsung. Metode kegiatan menggunakan (1) metode ceramah yakni untuk menyampaikan pengetahuan secara umum tentang hidroponik dan bank sampah disertai dengan sesi tanya jawab dan (2) metode pembelajaran digunakan untuk alih pengetahuan atau ketrampilan dan system nilai yang dimiliki oleh nara sumber kepada anggota masyarakat. Masalah yang dihadapi di lapangan adalah masalah gerakan menanam dengan metode Hidroponik, pengelolaan bank sampah, dan pemanfaatan sampah plastic menjadi produk recycle. Pemecahan masalah yang dapat dilakukan dengan pendampingan yaitu memberikan pengetahuan, pemahaman, dan pelatihan.
\end{abstract}

Kata kunci: Pemberdayaan Masyarakat; Pendampingan dan Manajemen Lingkungan; Hidroponik dan Bank Sampah

\begin{abstract}
This dedication activity aims to build community awareness in the city of Bekasi to be able to 'friends ' with the surrounding environment to benefit directly. Methods of activities using (1) lecture methods are to convey knowledge in general about hydroponics and waste banks accompanied by question and answer sessions (2) Learning methods used to control knowledge or skills and value system Owned by the community members. Problems faced in the field is the problem of planting movements with hydroponic methods, management of waste banks, and utilization of plastic waste into recycle products. Troubleshooting that can be done with mentoring is to provide knowledge, understanding, and training.
\end{abstract}

Keywords: Community Empowerment; Environmental Assistance and Management; Hydroponics and trash Banks

\section{A. LATAR BELAKANG}

Siswandi dan Sarwono (2013) menyatakan bahwa hidroponik menjadi alternatif yang dapat digunakan untuk meningkatkan produktifitas tanaman terutama di lahan sempit (Siswandi dan Sarwono, 2013), (William, Suharto, \& Tanudjaja, 2016). Hidroponik adalah metode bercocok tanam dengan menggunakan media tanam selain tanah, seperti batu apung, kerikil, pasir, sabut kelapa, potongan kayu atau busa yang dilakukan karena fungsi tanah sebagai pendukung akar tanaman dan perantara larutan nutrisi dapat digantikan dengan mengalirkan atau menambah nutrisi, air dan oksigen melalui media tersebut (Roidah, 2014). Hidroponik merupakan salah satu cara bercocok tanam yang memanfaatkan air sebagai media nutrisi yang akan langsung diserap oleh tanaman sebagai penunjang tumbuh tanaman (Rakhman, Lanya, Bustomi Rosadi, \& Zen Kadir, 2015); dapat diaplikasikan di perkotaan maupun di pedesaan yang hemat air dan tempat serta pemeliharaannya mudah dan dapat dipanen sepanjang tahun (Surtinah, 2016). 
Penerapan sistem pertanian hidroponik di wilayah Kel. Jati Luhur dan Kel. Jati Sari sudah ada tetapi relatif masih baru. Animo masyarakat sekitar cukup besar untuk turut serta menerapkan bercocok tanam dengan hidroponik di rumah mereka masing-masing, tetapi keterbatasan ilmu pengetahuan dan penguasaan teknologi hidroponik, serta modal penyediaan sarana dan prasarana menjadi faktor pembatas penerapannya. Dengan adanya keterbatasan tersebut, maka kami tertarik untuk melakukan program mengenai hidroponik.

Selain melakukan program mengenai hidroponik, juga akan dilakukan program pengelolaan sampah (bank sampah). Pengelolaan sampah tidak hanya menjadi kewajiban pemerintah saja. Masyarakat dan pelaku usaha sebagai penghasil sampah juga harus bertanggung jawab menjaga lingkungan agar tetap bersih dan sehat. Mengacu pada UUPS, untuk mengatasi masalah dibutuhkan program-program pengelolaan sampah yang berbasis zero waste agar tidak hanya menjadi timbunan sampah di TPA, tetapi menjadi sesuatu barang yang memiliki nilai guna dan nilai jual (Sudanti, Andary, \& Yusmiati, 2019).

Partisipasi masyarakat akan program-program tersebut dipengaruhi oleh persepsi masyarakat terhadap suatu kegiatan. Persepsi memiliki pengertian berupa proses penginderaan dan penafsiran rangsangan suatu objek atau peristiwa yang diinformasikan sehingga seseorang dapat memandang, mengartikan, dan menginterpretasikan rangsangan yang diterima sesuai dengan keadaan dirinya dan lingkungan di mana ia berada sehingga ia dapat menentukan tindakannya (Diwyacitra, 2014).

Lokasi KKN tematik regular saat ini berada di Kelurahan Jati Luhur, Kec. Jati Asih. Kelurahan Jati Luhur berdasarkan luas wilayah di bagi menjadi $12 \mathrm{RW}$ dan $73 \mathrm{RT}$ yang terdiri dari $4 \mathrm{RW}$ berada di perumahan dan $8 \mathrm{RW}$ berada di lingkungan perkampungan. Berdasarkan hasil pra survey mahasiswa/i KKN, permasalahan yang ada yaitu (1) tidak adanya potensi alam yang ada di lingkungan Kelurahan Jati Luhur, dikarenakan tidak ada lahan untuk bercocok tanam. Hanya sebatas pekarangan rumah yang sangat terbatas; (2) belum seluruhnya masyarakat menerapkan system bank sampah pada sampah rumah tangga. Melihat kondisi permasalahan diatas, maka program kegiatan yang akan dilakukan oleh mahasiswa/i KKN Universitas Bhayangkara Jakarta Raya adalah pemberdayaan masyarakat berbasis manajemen lingkungan, dimana memfokuskan pada program kegiatan penanaman secara hidroponik dan bank sampah untuk program kegiatan pokok dan tidak menutup kemungkinan adanya kegiatan bantu lainnya.

Adapun tujuan kegiatan ini yakni (1) Meningkatkan pengetahuan dan keterampilan masyarakat dalam sadar akan memanfaatkan lingkungan rumah yang terbatas dengan penggunaan media tanam hidroponik, (2) Meningkatkan pengetahuan dan kesadaran masyarakat untuk memilah jenis sampah sebagai kunci awal penerapan konsep 3R, (3) Meningkatkan pengetahuan dan keterampilan masyarakat dalam pengolahan sampah menjadi produk recycle (4) Terjalinnya kerjasama perguruan tinggi, pemerintah dan masyarakat dalam rangka pemberdayaan ekonomi masyarakat menuju pengolahan sampah mandiri dan terpadu, serta pemanfaatan lahan rumah yang baik dan mudah dengan menggunakan media tanam hidroponik. 


\section{B. METODE PELAKSANAAN}

Untuk menunjang kegiatan ini maka digunakan metode yang mendukung pelaksanaan kegiatan tersebut. Berikut ini adalah rincian metode pelaksanaan yang akan dilakukan yaitu:

1. Metode pengumpulan data

Digunakan untuk mengumpulkan data-data mengenai kegiatan yang sudah dan akan dilakukan pada masyarakat lingkungan serta permasalahan-permasalahan dilingkungan masyarakat yang belum terselesaikan.

2. Menentukan tema kegiatan yang akan diberikan.

Berdasarkan atas apa yang telah dilakukan dalam survei yang diuraikan secara rinci pada latar belakang sehingga tema kegiatan dapat segera ditentukan.

3. Mencari studi pustaka.

Studi pustaka adalah teknik pengumpulan data referensi dari berbagai jenis sumber keilmuan yang menunjang permasalahan yang sedang dicarikan solusinya.

4. Membuat materi penyuluhan atau pelatihan.

Berdasarkan studi pustaka yang telah dilakukan maka dibuatlah materi penyuluhan atau pelatihan.

5. Menyajikan penyuluhan atau pelatihan.

Penyuluhan atau pelatihan diberikan dengan metode ceramah dan praktek langsung akan materi tersebut.

\section{HASIL DAN PEMBAHASAN}

Lokasi Abdimas berada di Kelurahan Jati Luhur, Kec. Jati Asih. Kelurahan Jati Luhur berdasarkan luas wilayah di bagi menjadi 12 RW dan $73 \mathrm{RT}$ yang terdiri dari $4 \mathrm{RW}$ berada di perumahan dan $8 \mathrm{RW}$ berada di lingkungan perkampungan. Berdasarkan hasil pra survey, permasalahan yang ada yaitu (1) tidak adanya potensi alam yang ada di lingkungan Kelurahan Jati Luhur, dikarenakan tidak ada lahan untuk bercocok tanam. Hanya sebatas pekarangan rumah yang sangat terbatas; (2) belum seluruhnya masyarakat menerapkan system bank sampah pada sampah rumah tangga; (3) belum dapat melihat manfaat sampah kering menjadi produk bernilai.

Masalah yang dihadapi dilapangan untuk: (a) Hidroponik, Belum semua masyarakat mencoba utnuk belajar mengenai penanaman dengan menggunakan hidroponik. Hal ini dikarenakan belum begitu tertarik untuk mempelajarinya dan media alat yang digunakan masih terbatas; (b) Bank Sampah, Masyarakat di tiap-tiap RW belum menerapkan system bank sampah, dimana belum diawali dengan memilah-milah antara sampah basah dan sampah kering rumah tangga; (c) Kewirausahaan dengan memanfaatkan produk recycle, masyarakat di tiap-tiap RW tidak melihat peluang/tidak memanfaatkan hasil dari sampah botol aqua, bungkus sachetan kopi, dan lain-lain.

Pemecahan masalah yang dapat dilakukan yaitu memberikan pengetahuan, pemahaman, dan pelatihan mengenai penyemaian dan pembuatan media tanam dengan cara hidroponik, dan pemanfaatan sampah kering yang dapat diolah menjadi produk yang memiliki nilai jual. Adapun uraian kegiatan yang telah dilakukan, yaitu: 


\section{Kegiatan Hidroponik}

Setelah dilakukan observasi melalui diskusi dan survei terhadap mitra, tahap berikutnya dari kegiatan ini yaitu workshop pelatihan bercocok tanam dengan teknik hidroponik, Kegiatan ini dilaksanakan di outdoor, mengingat untuk praktik cara bertanam dengan teknik hidroponik tempat yang dekat dengan kran air, dan akses mudah ke bahan baku. Pada kegiatan ini dilakukan dengan cara penyampaian materi hidroponik dan pelaksanaan praktik bercocok tanam dengan teknik hidroponik oleh peserta, meliputi kegiatan menyiapkan media tanam, bibit tanaman, pipa paralon, dan pengarahan tindakan selanjutnya yang harus dilakukan perserta setelah bibit selesai disemaikan. Secara singkat tahapan yang dilakukan oleh peserta selama praktik cocok tanam berjalan baik dan lancar.

Adapun alat dan bahan yang digunakan dalam kegiatan ini yakni: bibit, busa, dan tempat bibit sementara, pralon, box untuk menampung air, pembolong pralon, gelas bibit, kain flannel, dan pupuk. Berikut adalah dokumentasi kegiatan hidroponik.
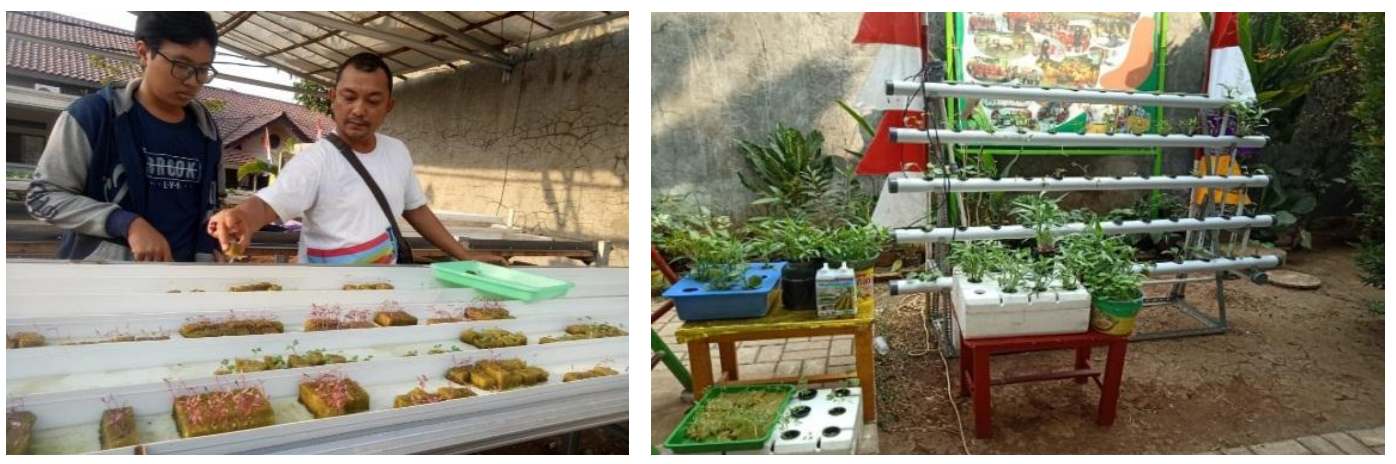

Gambar 1. Pelatihan Hidroponik

\section{Kegiatan Bank Sampah}

Tahap berikutnya dari kegiatan ini yaitu workshop pelatihan mengenai bank sampah mulai dari tujuan, manfaat, jenis sampah, sampai dengan pengolahan sampah yang bermanfaat, Kegiatan ini dilaksanakan di outdoor. Pada kegiatan ini dilakukan dengan cara penyampaian materi dan pelaksanaan praktik pemilahan jenis sampah hingga teknis di dalam bank sampah oleh peserta, meliputi kegiatan memilah sampah, menimbang, dan hasil dari penimbangan. Secara singkat tahapan yang dilakukan oleh peserta selama praktik berjalan baik dan lancar

Adapun alat dan bahan yang digunakan dalam kegiatan ini yakni: plastik, sampah, timbangan, buku tulis, dan pulpen. Berikut adalah dokumentasi kegiatan Bank Sampah
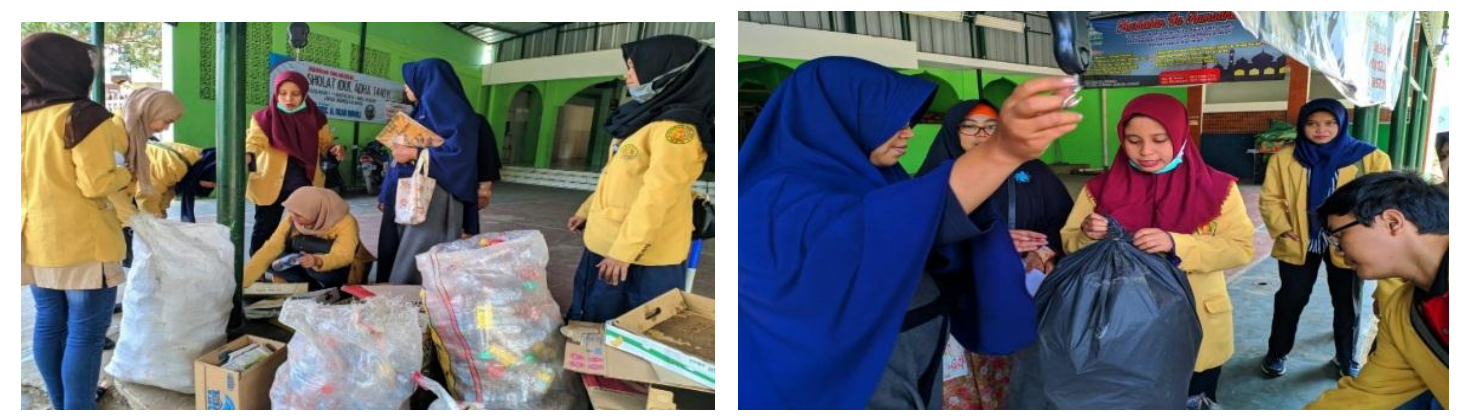

Gambar 2. Pelatihan Bank Sampah 


\section{Kegiatan Produk Recycle}

Tahap berikutnya dari kegiatan ini yaitu workshop pelatihan mengenai produk recycle, Kegiatan ini dilaksanakan di indoor. Pada kegiatan ini dilakukan dengan cara penyampaian materi dan pelaksanaan praktik pemilahan dari hasil sampah kering oleh peserta, meliputi kegiatan memilah sampah kering yang dapat diolah menjadi produk baru. Secara singkat tahapan yang dilakukan oleh peserta selama praktik berjalan baik dan lancer.

Adapun alat dan bahan yang digunakan dalam kegiatan ini yakni: sampah aqua botol dan bungkus kopi, gunting. Berikut adalah dokumentasi kegiatan Produk Recycle.
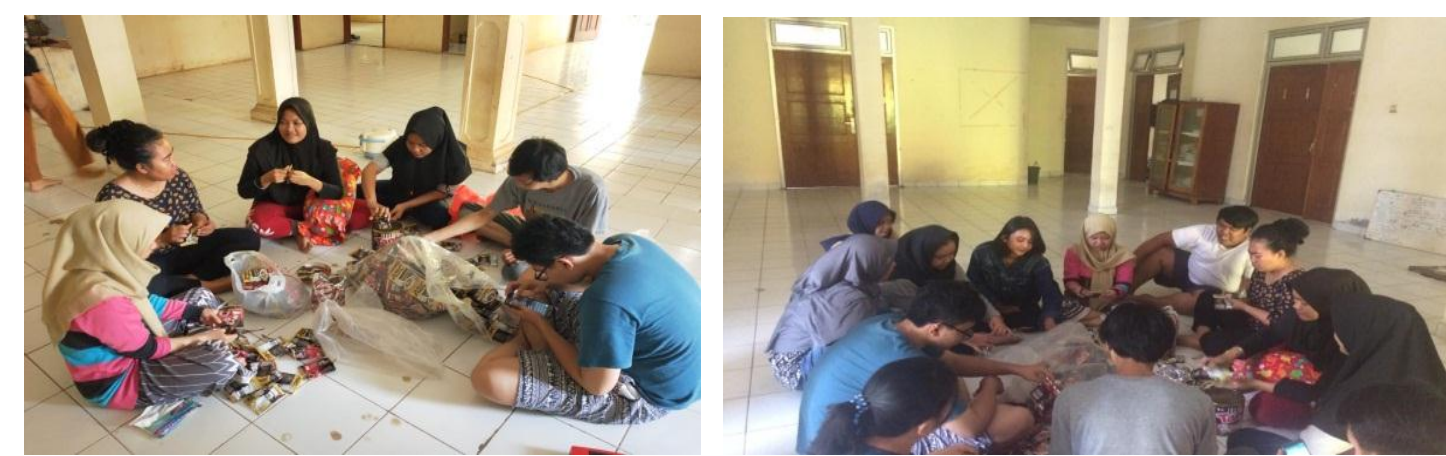

Gambar 3. Kegiatan Produk Recycle

Berdasarkan hasil ketiga kegiatan tersebut masih ditemukan kekurangan. Berikut rencana tindak lanjut dari kegiatan ini sesuai Tabel 1 berikut:

Tabel 1. Permasalahan Pasca Kegiatan dan Tindak Lanjut

\begin{tabular}{|c|c|c|c|c|}
\hline No. & $\begin{array}{l}\text { Aspek/Kom } \\
\text { ponen }\end{array}$ & Permasalahan & $\begin{array}{c}\text { Upaya Tindak } \\
\text { Lanjut }\end{array}$ & Program Kegiatan \\
\hline 1. & Hidroponik & $\begin{array}{l}\text { Belum semua } \\
\text { masyarakat } \\
\text { mencoba utnuk } \\
\text { belajar } \\
\text { mengenai } \\
\text { penanaman } \\
\text { dengan } \\
\text { menggunakan } \\
\text { hidroponik. Hal } \\
\text { ini dikarenakan: } \\
\text { a. Belum begitu } \\
\text { tertarik untuk } \\
\text { mempelajarinya. } \\
\text { b. Media alat } \\
\text { yang digunakan } \\
\text { masih terbatas. }\end{array}$ & $\begin{array}{l}\text { Perlu dilakukan } \\
\text { fasilitasi kepada } \\
\text { masyarakat untuk } \\
\text { mendorong agar } \\
\text { masyarakat mulai } \\
\text { tertarik untuk } \\
\text { menanam dengan } \\
\text { menggunakan } \\
\text { hidroponik. }\end{array}$ & $\begin{array}{l}\text { Memfasilitasi dalam } \\
\text { pendampingan } \\
\text { penanaman dengan } \\
\text { menggunakan } \\
\text { hidroponik. }\end{array}$ \\
\hline 2. & $\begin{array}{l}\text { Bank } \\
\text { Sampah }\end{array}$ & $\begin{array}{l}\text { Masyarakat di } \\
\text { tiap-tiap RW } \\
\text { belum } \\
\text { menerapkan } \\
\text { system bank } \\
\text { sampah, dimana } \\
\text { belum diawali } \\
\text { dengan } \\
\text { memilah-milah }\end{array}$ & $\begin{array}{l}\text { 1. Perlu dilakukan } \\
\text { fasilitasi untuk } \\
\text { mengajak } \\
\text { masyarakat } \\
\text { sadar akan arti } \\
\text { penting dan } \\
\text { bermanfaatnya } \\
\text { system bank } \\
\text { sampah untuk }\end{array}$ & $\begin{array}{l}\text { 1. Mendampingi } \\
\text { memfasilitasi } \\
\text { pembinaan } \\
\text { pemanfaatan } \\
\text { bank sampah. } \\
\text { 2. Mendampingi } \\
\text { memfasilitasi } \\
\text { pengelolaan } \\
\text { bank sampah. }\end{array}$ \\
\hline
\end{tabular}




\begin{tabular}{|c|c|c|c|c|}
\hline No. & $\begin{array}{c}\text { Aspek/Kom } \\
\text { ponen }\end{array}$ & Permasalahan & $\begin{array}{c}\text { Upaya Tindak } \\
\text { Lanjut }\end{array}$ & Program Kegiatan \\
\hline & & $\begin{array}{l}\text { antara sampah } \\
\text { basah dan } \\
\text { sampah kering } \\
\text { rumah tangga. }\end{array}$ & $\begin{array}{l}\text { kedepannya. } \\
\text { 2. Menyadarkan } \\
\text { masyarakat } \\
\text { akan tingginya } \\
\text { sampah } \\
\text { khususnya di } \\
\text { daerah Bekasi, } \\
\text { dengan melihat } \\
\text { peluang dan } \\
\text { memanfaatkan } \\
\text { sampah yang } \\
\text { ada. }\end{array}$ & $\begin{array}{l}\text { 3. Mendampingi } \\
\text { dengan } \\
\text { memfasilitasi } \\
\text { produk olahan } \\
\text { dari sisa } \\
\text { sampah kering } \\
\text { (seperti: aqua } \\
\text { botol, plastik } \\
\text { kopi sachet, dll) } \\
\text { menjadi produk } \\
\text { yang memiliki } \\
\text { nilai jual. }\end{array}$ \\
\hline 3. & $\begin{array}{l}\text { Produk } \\
\text { recycle }\end{array}$ & $\begin{array}{l}\text { 1) Masyarakat } \\
\text { di tiap-tiap RW } \\
\text { tidak melihat } \\
\text { peluang/tidak } \\
\text { memanfaatkan } \\
\text { hasil dari } \\
\text { sampah botol } \\
\text { aqua, bungkus } \\
\text { sachetan kopi, } \\
\text { dll. }\end{array}$ & $\begin{array}{l}\text { 3. Perlu dilakukan } \\
\text { fasilitasi untuk } \\
\text { mengajak } \\
\text { masyarakat } \\
\text { memanfaatkan } \\
\text { sampah botol } \\
\text { aqua, bungkus } \\
\text { sachetan kopi, } \\
\text { dll menjadi } \\
\text { produk yang } \\
\text { bernilai. } \\
\text { Menyadarkan } \\
\text { masyarakat } \\
\text { bahwa dengan } \\
\text { memanfaatkan } \\
\text { produk sampah } \\
\text { (recycle) } \\
\text { menjadi produk } \\
\text { bernilai akan } \\
\text { memberikan } \\
\text { tambahan } \\
\text { penghasilan } \\
\text { rumah tangga. }\end{array}$ & $\begin{array}{l}\text { 4. Mendampingi } \\
\text { memfasilitasi } \\
\text { pembinaan } \\
\text { pemanfaatan } \\
\text { sampah. } \\
\text { 5. Mendampingi } \\
\text { memfasilitasi } \\
\text { pengajaran } \\
\text { dalam membuat } \\
\text { produk dari } \\
\text { bahan sampah. } \\
\text { 6. Mendampingi } \\
\text { dengan } \\
\text { memfasilitasi } \\
\text { pemasaran dan } \\
\text { memperkenalka } \\
\mathrm{n} \text { produk recycle } \\
\text { ke pihak } \\
\text { luar/stakeholder } \\
\text {. }\end{array}$ \\
\hline
\end{tabular}

\section{SIMPULAN DAN SARAN}

Simpulan yang kami dapatkan dalam kegiatan ini adalah kegiatan pengabdian kepada masyarakat di Kelurahan Jati Luhur, Kecamatan Jati Asih, Kabupaten Bekasi mendapat sambutan, tanggapan dan perhatian yang cukup baik dari warga sekitar dan pejabat kelurahan setempat, program kegiatan yang diberikan kepada masyarakat dapat terealisasi dengan optimal dan lancar, bekal yang diberikan kepada masyarakat pada dasarnya, memberikan dukungan dan pengetahuan yang berdampak dampak positif, kegiatan pengabdian kepada masyarakat mempunyai tujuan di antaranya menjalin erat hubungan antara lembaga perguruan tinggi sebagai sumber ilmu pengetahuan dengan masyarakat dan pemerintah setempat terintegrasi dengan baik.

Sedangkan saran yang dapat kami berikan yaitu adanya program kegiatan berupa penyuluhan mengenai pengertian dan manfaat hidroponik, penyemaian bibit dan pembuatan media hidroponik ini diharapkan dapat 
menambah pengetahuan tentang memanfaatkan lahan atau pekarangan rumah dengan menggunakan media tanam hidroponik, adanya program kegiatan berupa penyuluhan mengenai pengertian dan manfaat bank sampah, karakteristik sampah (sampah basah dan sampah kering), dan pengelolaan bank sampah ini diharapkan dapat menambah pengetahuan dan meningkatkan kesadaran masyarakat akan sampah dan manfaat sampah jika dikelola dengan baik dan diharapkan dengan adanya program kegiatan hidroponik dan bank sampah dapat memberikan dampak pada peningkatan kesadaran masyarakat akan arti penting manajemen lingkungan.

\section{Ucapan Terima Kasih}

Ucapan terima kasih kami sampaikan kepada semua pihak yang telah membantu pelaksanaan kegiatan pengabdian kepada masyarakat ini, yaitu: (1) Dr. Drs. H. Bambang Karsono, S.H., M.M. Selaku Rektor Universitas Bhayangkara Jakarta Raya, (2) Kepala Kelurahan Jati Luhur, staf dan jajarannya serta masyarakat setempat atas perhatian dan kerjasamanya sehingga kami dapat melaksanakan kegiatan ini, (3) Tim dosen dan mahasiswa/I yang telah membantu dalam kegiatan pengabdian kepada masyarakat ini, dan Semua pihak yang telah membantu dalam pelaksanaan kegiatan ini, yang tidak bisa kami sebutkan satu persatu.

\section{DAFTAR RUJUKAN}

Diwyacitra. (2014). Persepsi dan partisipasi masyarakat dalam pengelolaan sampah rumah tangga. Institut Pertanian Bogor.

Rakhman, A., Lanya, B., Bustomi Rosadi, R. A., \& Zen Kadir, M. (2015). Pertumbuhan Tanaman Sawi Menggunakan Sistem Hidroponik Dan Akuaponik. Jurnal Teknik Pertanian Lampung, 4(4), 245-254.

Roidah, I. S. (2014). Pemanfaatan Lahan Dengan Menggunakan Sistem Hidroponik. Jurnal Universitas Tulungagung BONOROWO Tahun, 1(2), 4350 .

Siswandi, \& Sarwono. (2013). Uji Sistem Pemberian Nutrisi dan Macam Media terhadap Pertumbuhan dan Hasil Selada (Latuca sativa L.) Hidroponik. Jurnal Agronomika, 8(1), 144-148.

Sudanti, S., Andary, H. A., \& Yusmiati, S. (2019). Analisis Pengolahan Sampah Berbasis Zero Waste sebagai Salah Satu Upaya Universitas Semarang (USM) mewujudkan Eco-Campus. Teknika, 6. https://doi.org/10.26623/teknika.v12i1.1186

Surtinah, S. (2016). Keberadaan Oksigen Pada Media Tanam Hidroponik terhadap Pertumbuhan Tanaman Sayuran (Presence of Oxygen At Hydroponic Growing Media on the Growth of Vegetables). Jurnal BiBieT, 1(1), 27. https://doi.org/10.22216/jbbt.v1i1.1249

William, Suharto, H., \& Tanudjaja, H. (2016). Sistem Pemantauan dan Pengendalian Parameter Lingkungan Pertumbuhan Pada Tanaman Hidroponik. Tesla, 18(2), 188-207. 